\title{
Fabrication of Modified MMT/Glass/Vinylester Multiscale Composites and Their Mechanical Properties
}

\author{
Garima Mittal, ${ }^{1}$ Vivek Dhand, ${ }^{1}$ Ji Il Ryu, ${ }^{1}$ Kyong Yop Rhee, ${ }^{1}$ \\ Hyeon-Ju Kim, ${ }^{2}$ and Dong Ho Jung ${ }^{2}$ \\ ${ }^{1}$ Department of Mechanical Engineering, College of Engineering, Kyung Hee University, Yongin 446-701, Republic of Korea \\ ${ }^{2}$ Korea Research Institute of Ships and Ocean Engineering, Daejeon 305-600, Republic of Korea \\ Correspondence should be addressed to Kyong Yop Rhee; rheeky@khu.ac.kr
}

Received 14 May 2015; Revised 21 August 2015; Accepted 23 August 2015

Academic Editor: Christian Brosseau

Copyright (C) 2015 Garima Mittal et al. This is an open access article distributed under the Creative Commons Attribution License, which permits unrestricted use, distribution, and reproduction in any medium, provided the original work is properly cited.

Montmorillonite (MMT) may become a preferred filler material for fiber-reinforced polymer (FRP) composites due to its high aspect ratio, large surface area, and low charge density. In the present paper, MMT/glass/vinylester multiscale composites are prepared with untreated and surface-treated MMT clay particles with an MMT content of $1.0 \mathrm{wt} \%$. Effects of surface treatment on mechanical properties of MMT/glass/vinylester multiscale composites are investigated through tensile and bending tests, which revealed enhanced mechanical properties in the case of surface-treated MMT. Thermal properties are studied through thermogravimetric analysis (TGA) and dynamic mechanical analysis (DMA). X-Ray diffraction is performed to investigate the interaction between MMT and the matrix. Fourier Transform Infrared (FTIR) is also performed for both untreated and surfacetreated MMT. Furthermore, Field Emission-Scanning Electron Microscope (FE-SEM) is conducted to investigate the path of fracture propagation within the composite surface, showing that the surface-treated MMT based multiscale composite has better interactions with the host matrix than the untreated MMT multiscale composites. These composites with enhanced mechanical strength can be used for various mechanical applications.

\section{Introduction}

Over the last few decades, polymer composites reinforced with fillers such as whiskers, fibers, particles, and platelets have supplanted many established materials in various fields [1-4]. Due to ease of processing, light weight, and low cost, polymer composites are of interest to various industries. Properties of composites depend upon properties of the matrix and filler material used to reinforce the matrix. The foremost concern is to expand the application spectrum of these polymer composites by augmenting or altering the properties of the existing materials. To accomplish this objective, surface modification techniques involving chemical, physical, or biological modification of the reinforced material are performed [5-9]. Due to surface functionalization, the interfacial interactions between the fillers and matrix increase, thereby improving the mechanical and thermal properties [10]. Additionally, surface functionalization decreases agglomeration of reinforced material and helps to achieve optimal dispersion. For instance, Du et al. modified the MWNT surfaces with $\mathrm{MgO}$ and observed an enhancement of $89 \%$ in thermal conductivity of $\mathrm{MgO}$ functionalized MWNT in epoxy matrix [11]. Olivier et al. studied the increase in stability and corrosion protection of galvanized steel by an aqueous layer of silanized MMT [12]. Lee et al. recycled the carbon fiber by reestablishing the mechanical and chemical properties through plasma treatment of carbon fiber surface [13].

MMT clay particles are widely used filler materials with unique properties. MMT is a layered structure of parallel sheets arranged in a $2: 1$ ratio of tetrahedral/octahedral crystal structure with $\sim 1 \mathrm{~nm}$ interplanar distance. $\mathrm{Na}^{+}$or $\mathrm{K}^{+}$ions and water molecules reside between these layers to maintain its negative electric charge. MMT possesses a high 


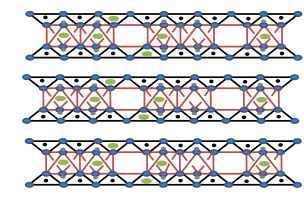

Clay

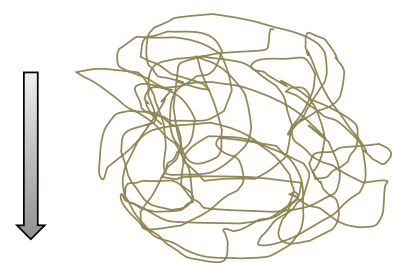

Polymer
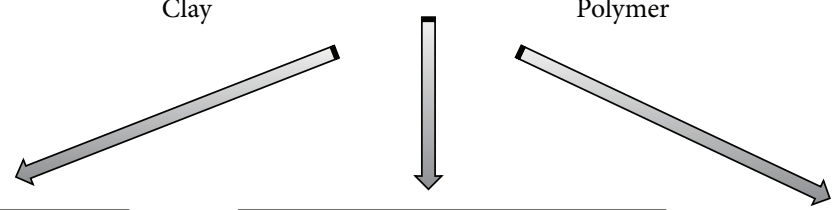

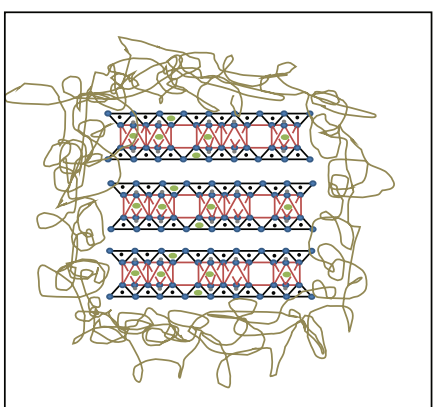

Unmixed

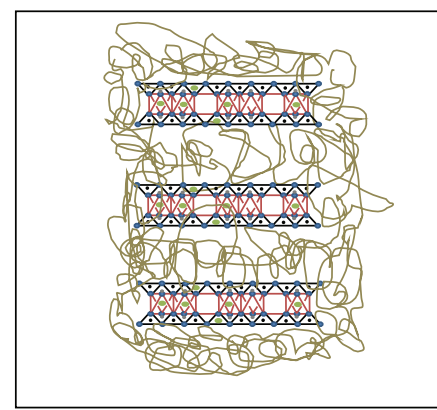

Intercalated

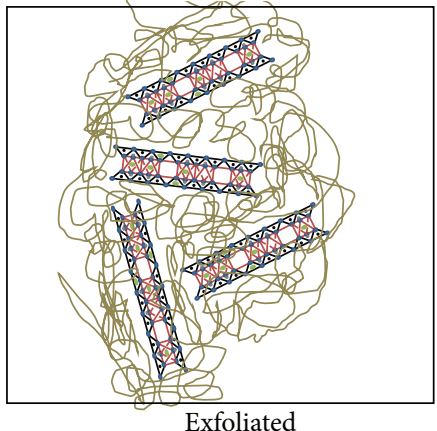

Exfoliated

FIGURE 1: Schematic representation of forms of composite structures depending upon clay/polymer interactions.

aspect ratio, large surface area $\left(750 \mathrm{~m}^{2} / \mathrm{g}\right)$, and low surface charge density $\left(0.25-0.5\right.$ equiv. $\left.\mathrm{mol}^{-1}\right)[14,15]$. Because of the low surface charge density, the layers can be separated and chemically modified by ion exchange reactions, which consequently improve the mechanical and thermal properties of the host material [16]. In ion exchange reactions, $\mathrm{Na}^{+}$or $\mathrm{K}^{+}$ ions are replaced by quaternary or onium ions, which changes hydrophilic MMT into hydrophobic MMT. Consequently, the compatibility and interactions between the MMT layers and polymer matrix increase for polymers that are hydrophobic in nature [17-20]. Additionally, increases in surface adhesive force and intercalation or exfoliation occur between MMT layers. Thus, surface-treated MMT-reinforced composites can enhance composite properties [21-23]. Generally, three types of interfacial interactions occur between MMT layers and the polymer matrix depending upon processing and the degree of MMT dispersion [24] (Figure 1). In unmixed composites, interactions between the polymer and MMT are very weak. For intercalated composites, polymer chains intercalate into MMT layers by maintaining the MMT morphology. In exfoliated form, maximum polymer/MMT interaction occurs and MMT layers are separated and dispersed into the polymer matrix by an average nanometer distance, allowing the MMT particles to behave as nanoentities [25, 26].

Thermoset polymer vinylester is among the most widely used polymers due to its excellent barrier and thermal properties, chemical stability, corrosion resistance, light weight, low cost, and ease of processing [27-29]. Pure vinylester is brittle; to overcome this limitation, the resin is reinforced or reacted with various fillers or modifiers $[30,31]$. The most often used filler material with pure vinylester is glass fiber. In the past few years, glass fiber-reinforced plastics (GFRPs) have fascinated scientists in research and industry. Due to their high strength, high stiffness, durability, high chemical resistance, and less brittle nature, glass fibers are widely used as fillers in polymer matrices [32]. A number of studies have shown enhanced properties of the vinylester matrix due to addition of glass fiber/mat reinforcements [33,34].

In the present study, GFRP/vinylester composites with MMT (Cloisite $\mathrm{Na}^{+}$) are synthesized. The effects of the surface modification of the system are studied using untreated and treated MMT, where 3-aminopropyltriethoxysilane (3APTES) is used as a surface modifier for MMT. Though much work has been carried out on surface-functionalized fillers, MMT with vinylester is a less explored area. Therefore, a comparative mechanical study is performed herein for both untreated and surface-treated MMT clay-based GFRP/vinylester composites. To study the effects of surface treatment of MMT on mechanical properties, tensile and bending tests are performed. To study the morphology of the fractured surface, FE-SEM is performed and thermal studies are conducted using TGA and DMA. XRD and FTIR are also utilized to better understand this system.

\section{Experimental Section}

2.1. Materials. The matrix resin used in this study is Vinylester SR 830 with viscosity $1.5 \sim 1.7$ poise at $25^{\circ} \mathrm{C}$ and life time $25 \sim 30 \mathrm{~min}$ at $25^{\circ} \mathrm{C}$ and the hardener type benzoyl peroxide (BPO) is used. Untreated MMT clay $\left(\right.$ Cloisite $\mathrm{Na}^{+}$) with $11.7 \AA ̊ d$-spacing and $92.6 \mathrm{meq} / 100 \mathrm{~g}$ clay 
cation exchange capacity is used. Surface coupling agent 3aminopropyltriethoxysilane (3-APTES) is purchased from Aldrich Chemical Co., USA. Chopped strands glass mat of E type glass $\left(380 \mathrm{~g} / \mathrm{m}^{2}\right)$ is used.

\subsection{Surface Treatment of MMT Nanoclay (Silanized MMT).} Surface treatment of MMT clay was carried out in following steps. First, separate aqueous solutions of untreated MMT $(1 \mathrm{~g})$ and 3-aminopropyltriethoxysilane were prepared separately in distilled water (10 $\mathrm{g}$ and $4 \mathrm{~g}$, resp.) which were further mixed with ethyl alcohol $(20 \mathrm{~g}$ and $12 \mathrm{~g}$, resp.), for $5 \mathrm{~h}$ at $50^{\circ} \mathrm{C}$ and $2 \mathrm{~h}$ at $25^{\circ} \mathrm{C}$, respectively. Later, these two solutions of untreated MMT and 3-aminopropyltriethoxysilane were mixed together with continuous stirring for $3 \mathrm{~h}$ at $25^{\circ} \mathrm{C}$. This prepared solution was filtered and followed by thorough washing with distilled water and drying for $48 \mathrm{~h}$ at $80^{\circ} \mathrm{C}$ in vacuum conditions.

2.3. Synthesis of GFRP/Vinylester/MMT Composites. The composites of MMT (as-received and treated) based GFRP vinylester were synthesized by mixing of $1.0 \mathrm{wt} . \%$ MMT powders (as-received and treated) into $100 \mathrm{~g}$ of vinylester resin with continuous stirring at room temperature for $1 \mathrm{~h}$. Later, $1.0 \mathrm{wt} . \%$ of hardener BPO was mixed into the above mixer. Afterwards, the ensuing mixer was poured over the 5 plies of chopped strands glass mats of $20 \times 20 \mathrm{~cm}^{2}$ dimensions and pressed into a mold at $110^{\circ} \mathrm{C}$ and 4 bar for 10 minutes. Finally, multiscale composites plates were prepared for further investigations.

2.4. Characterization. X-ray diffraction characterization is done to study the effect of surface treatment of MMT clay, using $\mathrm{Cu} \mathrm{K \alpha}$ radiation with $\lambda 0.1542 \mathrm{~nm}$ at $40 \mathrm{KV}$ and $100 \mathrm{~mA}$. Scan is taken from $3^{\circ}$ to $90^{\circ}$ with 0.02 steps. Degree of dispersion of MMT clay sheets is investigated by interlayer spacing by Bragg's equation $(n \lambda=2 d \sin \theta)$ [35]. FTIR spectrum is taken to analyze the chemical changes in MMT with surface treatment. The data are taken in the range from 4000 to $400 \mathrm{~cm}^{-1}$. To analyze the thermal effect on the system, TGA and DMA are performed. TGA analysis is done on heating rate of $10^{\circ} \mathrm{C} / \mathrm{min}$ in temperature range of $30^{\circ} \mathrm{C}$ to $700^{\circ} \mathrm{C}$ by TGA SQT 600 model. To understand the viscoelastic behavior of the system, DMA study is done from $15^{\circ} \mathrm{C}$ to $260^{\circ} \mathrm{C}$ at a constant heating rate of $5^{\circ} \mathrm{C} / \mathrm{min}$ and frequency of $1 \mathrm{~Hz}$ in the presence of $\mathrm{N}_{2}$ gas. To study the fracture surface of the sample, SEM is performed. Samples are coated with gold before SEM. To study the mechanical properties of GFRP/Vinylester based MMT composites, tensile and bending tests are performed. For Tensile tests, ASTM D638 specimens are cut from composite sheet and then tested with Instron universal testing machine (UTM). Stress-strain behavior of GFRP/vinylester/MMT composites is studied through tensile tests. To analyze the maximum flexural strength and flexural modulus, bending tests are examined. Bending sample dimensions are $130 \times 25 \times(1.7 \pm$

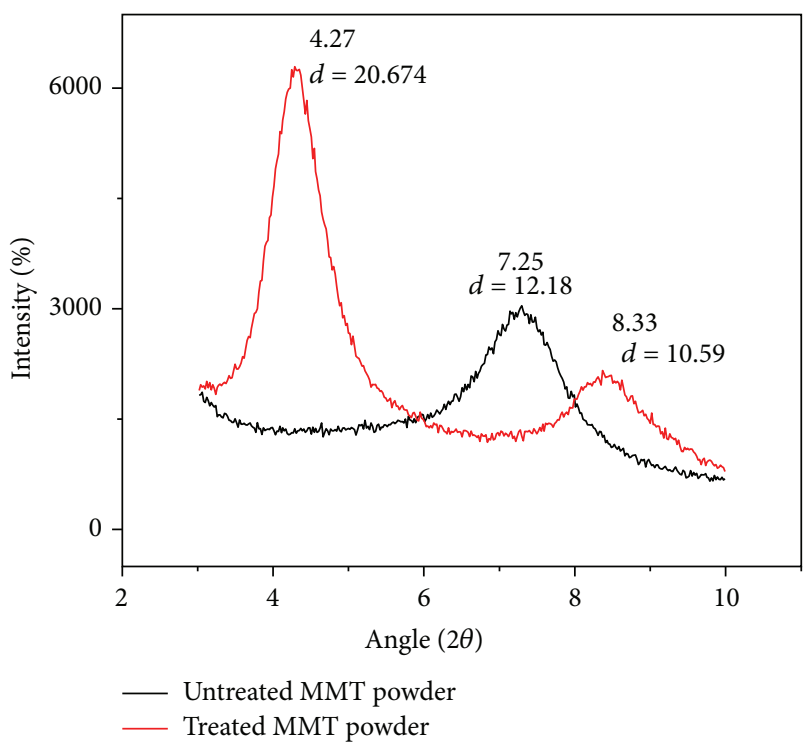

FIgURE 2: X-Ray diffraction spectra of untreated and treated MMT powders.

0.5) mm. Reproducibility of the tensile and bending tests has also been checked.

\section{Results and Discussions}

To study the effect of surface treatment on MMT interlayer spacing, XRD is performed. Figure 2 presents the XRD pattern of untreated and treated MMT powders. XRD data provides the details about $d$-spacing and dispersion of MMT platelets after silanization. As can be seen in Figure 2, $2 \theta$ value for untreated MMT powder is 7.28, which corresponds to an interlayer spacing of $12.12 \AA$. For silanized MMT powder, the peak shifted to 4.29 , corresponding to $d$-spacing of $20.55 \AA$. This result suggests that interlayer spacing increases due to the surface treatment [36]. When MMT is treated with 3APTES, $\mathrm{Na}^{+}$and $\mathrm{K}^{+}$ions are exchanged with quaternary ions, which are responsible for the expansion of the distance between layers compared to that in the untreated MMT [23]. Figure 3 shows the XRD spectra of vinylester/GFRP composites with $1.0 \mathrm{wt} . \%$ untreated and treated MMT, respectively. In both cases, there is a shift in peak to lower angle. For untreated MMT, the peak shifts to $2 \theta$ value of 6.95 ( $d$-spacing of $12.70 \AA$ ), while the shift for silanized MMT is to $2 \theta$ value of 3.94 ( $d$-spacing of $22.40 \AA$ ). There is more change in $d$ spacing for silanized MMT compared to the untreated MMT, indicating that vinylester entered between the silanized MMT layers, resulting in exfoliation and dispersion of the layers into the matrix. Conversely, there are some layers that are not exfoliated and remained in the original form, representing one additional peak at around $2 \theta=8.40^{\circ}$ [37].

FTIR is performed in order to analyze the effect of 3APTES surface treatment on MMT. FTIR spectra of untreated and surface-treated MMT powders are shown in Figure 4. The following typical characteristic peaks of MMT are observed in both the conditions: peak at $3627 \mathrm{~cm}^{-1}$ that is 


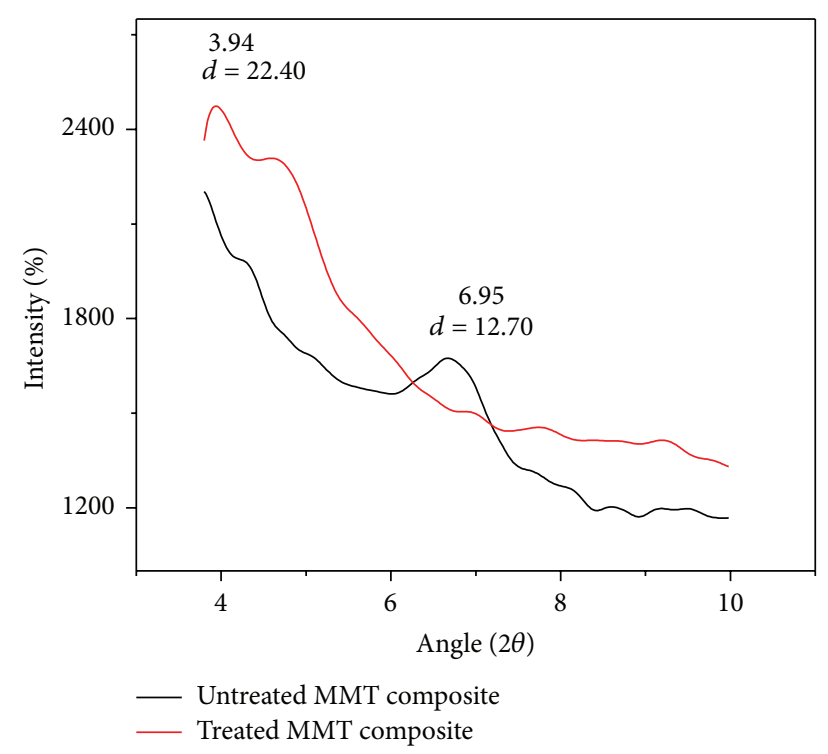

FIGURE 3: X-Ray diffraction spectra of untreated and treated MMT based GFRP/vinylester composites.

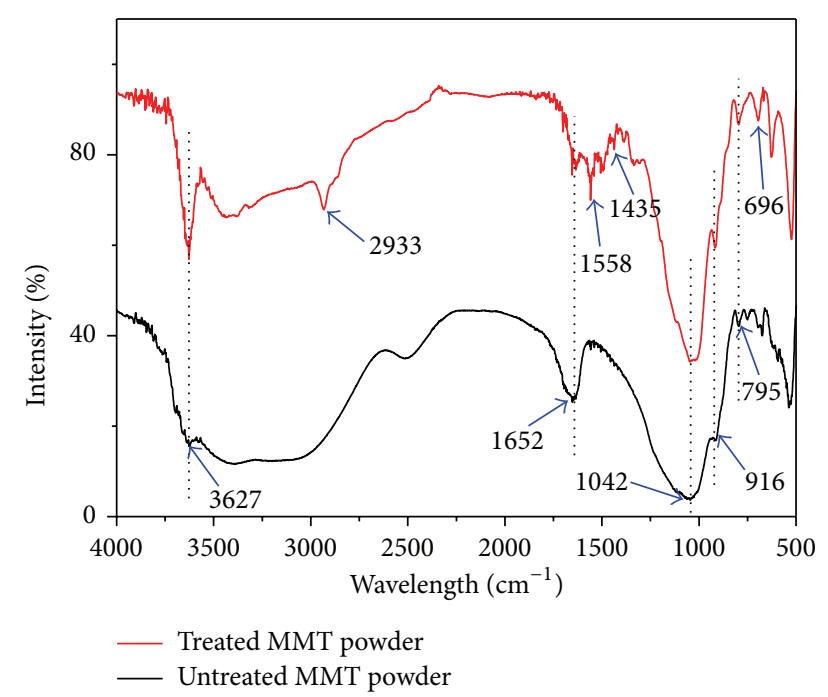

FIGURE 4: FTIR spectra of untreated and treated MMT powders.

assigned to the stretching of hydroxyl groups bound to $\mathrm{Al}^{+}$ or $\mathrm{Mg}^{+}$, a very strong peak at $1042 \mathrm{~cm}^{-1}$ that represents the $\mathrm{Si}-\mathrm{O}$ bond stretching in silicates, and small peaks at $916 \mathrm{~cm}^{-1}$ that is assigned to the bending vibrations of $\mathrm{Al}(\mathrm{Al}) \mathrm{OH}$ and at $795 \mathrm{~cm}^{-1}$ for bending vibrations of $\mathrm{Mg}(\mathrm{Mg}) \mathrm{OH}$. However, new peaks for silanized MMT powder are observed at around $2933 \mathrm{~cm}^{-1}$ because of $-\mathrm{CH}$ asymmetric stretching and $-\mathrm{CH}_{2}$ symmetric stretching which validate the attachment of organic silane on the MMT surface at 1558, 1435, and $696 \mathrm{~cm}^{-1}$ due to $-\mathrm{NH}_{2}$ and $-\mathrm{CH}_{2}$ bending vibrations. The peak intensities also decrease after surface treatment, which provide evidence of surface modification of MMT powder after 3-APTES treatment [36].
Figure 5 represents the TEM images of layered structure of untreated (a) and treated MMT (b). In the case of untreated MMT, the stacks of multiple layers are observed which represent the aggregated form of the layers which has less $d$ spacing. Meanwhile the thin dispersed layers are observed in case of treated MMT which shows the modification has been done due to the treatment of 3-APTES. The interlayer distance has also increased after treatment which verifies that the exfoliation of MMT has taken place. The surface of the treated MMT is rougher than the untreated one which validates the reason behind increased mechanical properties.

SAED patterns (inset) also show the changes after surface treatment. As can be seen in the images, MMT before treatment is comparatively more crystalline in nature, while after treatment it becomes amorphous. The increase in $d$ spacing due to ion exchange reaction is the reason behind this.

Thermal studies of both composites were done through TGA and DSC curves. Figure 6 shows the weight loss and heat flow curve of untreated (a) and treated (b) MMT based composites. It can be seen in the obtained thermograms that both composites show one-step degradation. The onset degradation temperatures are $420.90^{\circ} \mathrm{C}$ and $433.34^{\circ} \mathrm{C}$ for untreated and treated MMT based composites, respectively, which correspond to the DSC endothermic decomposition peaks. Compared to untreated MMT based composites, the thermal stability of the treated MMT based composites is better. Additionally, the weight loss \% for the untreated MMT based composites is higher (33.77\%) than the treated one $(32.08 \%)$ and therefore the mass residue is lower. This difference in thermal stability may be because of the fact that the presence of MMT layers into the matrix acts as thermal barrier during the decomposition and provide stability. When the MMT powder is treated with 3-APTES, silane moieties are attached and the interplanar distance between MMT layers increases [23]. Consequently, individual layer behaves as nanoentity and distributes evenly into the matrix [38]. Hence, because of enhanced interactions and bonding, thermal stability of the treated MMT based composites increases. Furthermore, same pattern was followed by DSC curves. Thermograms of both untreated and treated MMT based composites demonstrate the same pattern, indicating an endothermic process. The degradation temperature of the treated MMT based composites is higher which may be because of cross-linking between the matrix and the reinforced material and constrained movement of the matrix fragments due to the good distribution of the MMT after surface treatment [34].

The viscoelastic behavior of the system is studied using DMA. Figure 7 presents the storage modulus and $\tan \delta$ value of the vinylester/GFRP composites containing untreated and treated MMT. It can be seen from Figure 7(a) that for both cases storage modulus starts decreasing with increasing the temperature $\left(T_{g}\right)$ and displays a rubbery plateau. This state is the change from glassy state to rubbery state (glass transition) because at higher temperature the molecular segments start to move with the load which may cause the destruction of the cross-links between the host and fillers. During these chemicomechanical changes there is insufficient energy to 


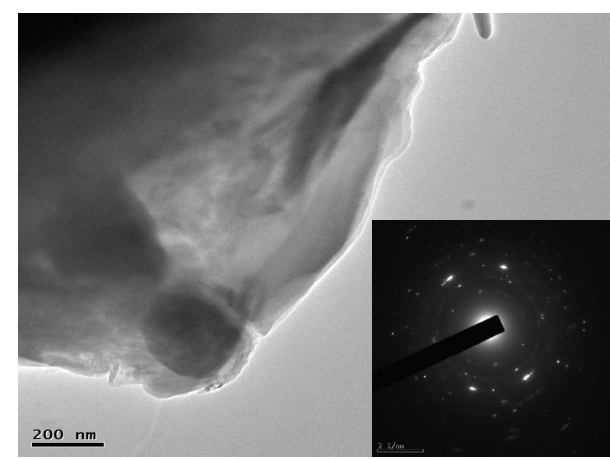

(a)

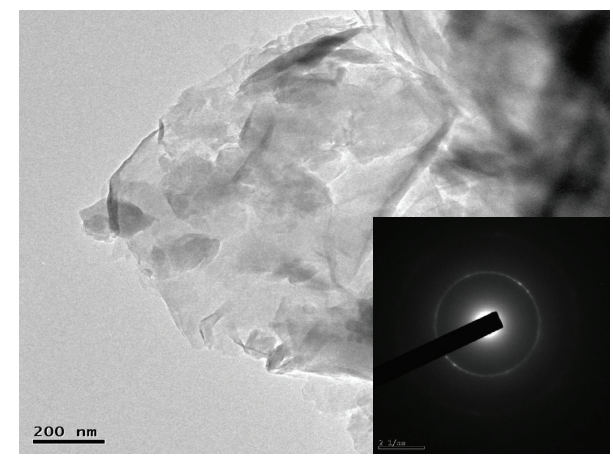

(b)

FIGURE 5: TEM images of untreated (a) and treated (b) MMT powders (inset: SAED pattern, resp.).

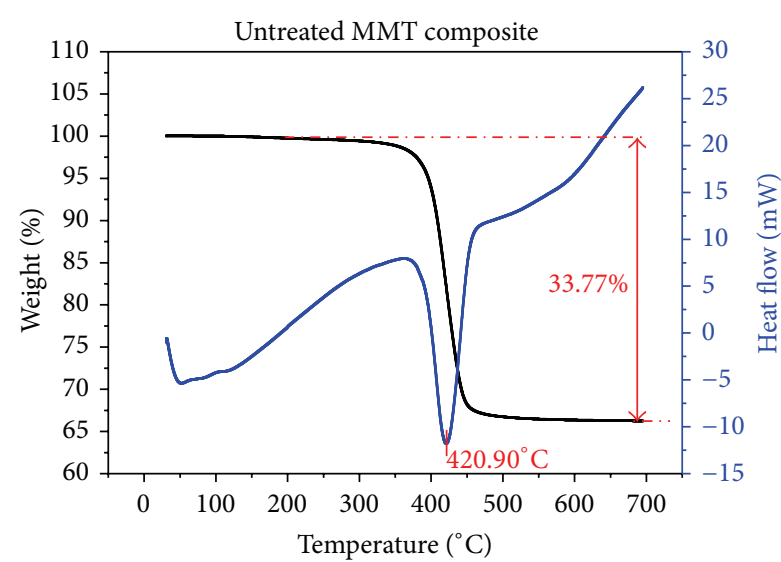

(a)

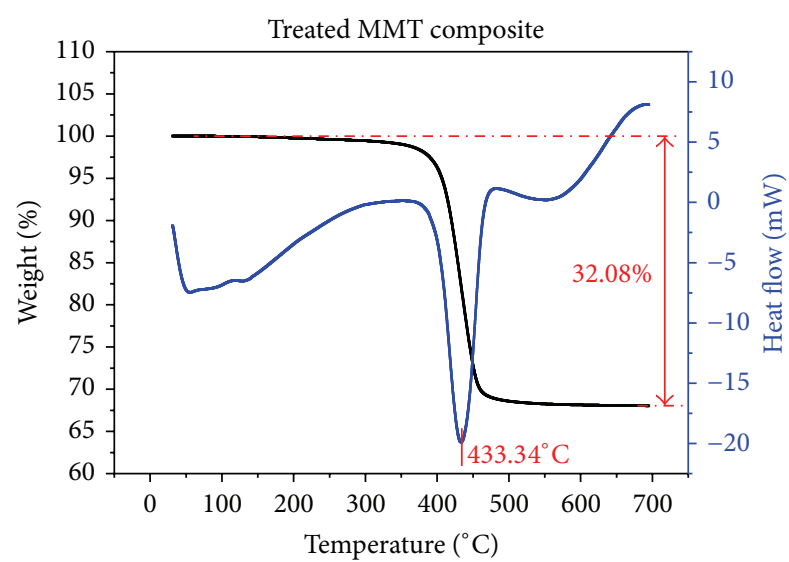

(b)

FIGURE 6: TGA and DSC thermograms of untreated (a) and treated (b) MMT based GFRP/vinylester composites.

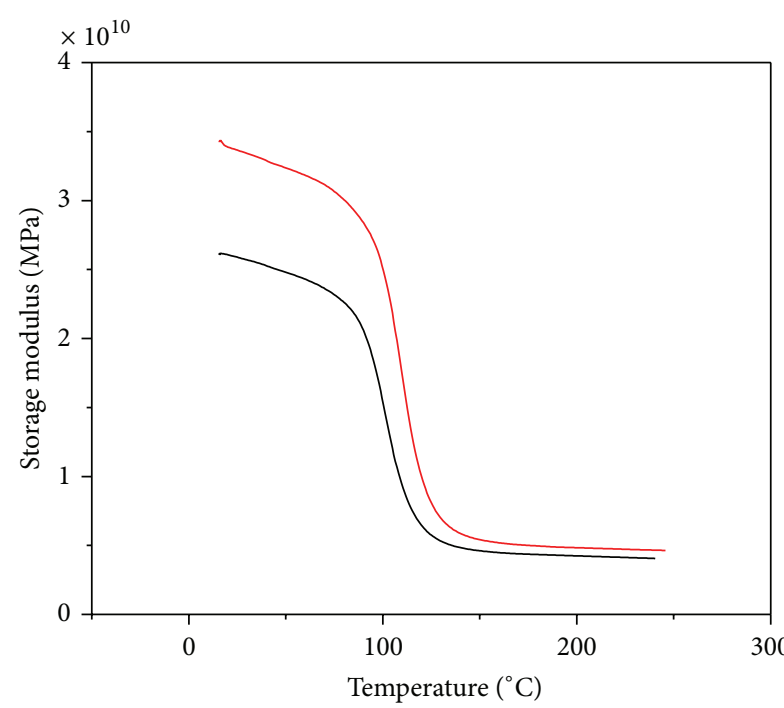

- Untreated MMT composite Treated MMT composite

(a)

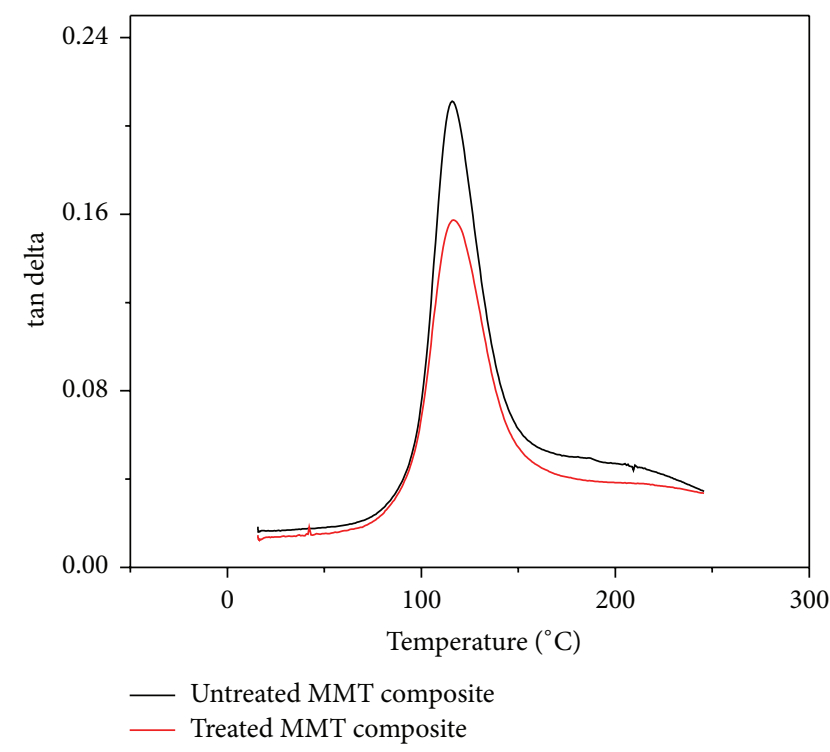

(b)

FIGURE 7: DMA graphs of untreated and treated MMT based GFRP/vinylester composites. 


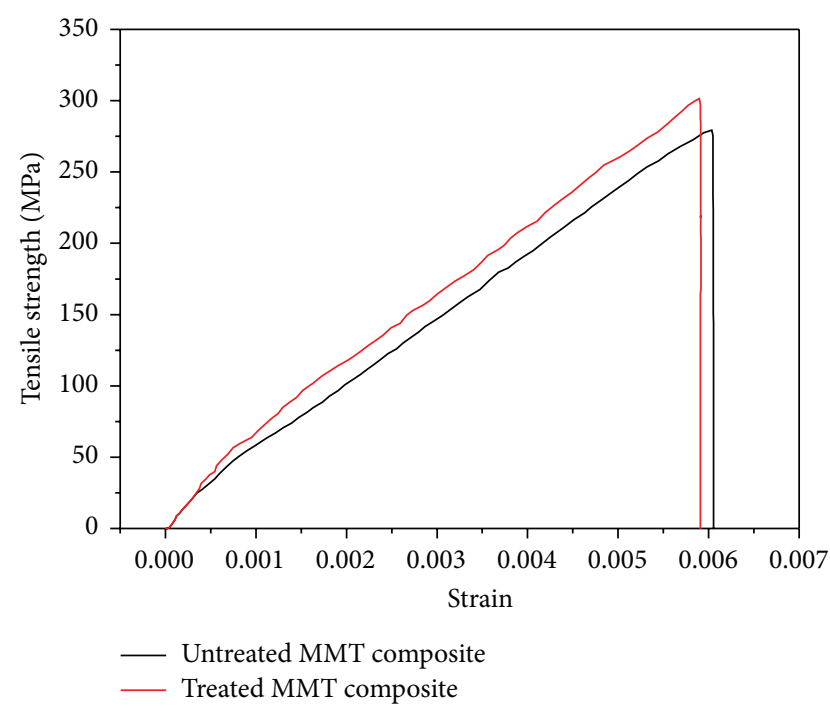

Figure 8: Stress-strain curve of tensile specimens of untreated and treated MMT based GFRP/vinylester composites.

surpass the glass region barrier. The storage modulus of silane-treated MMT composite is higher than that of the untreated one because after treatment interaction between the matrix and the filler increases and MMT layers act as nanoentities which contributes to stress sharing during load application and hinders the mobility of the molecules. Storage modulus depends upon the aspect ratio of the fillers [39]. As aspect ratio increases, stress sharing between the fillers and host also increases consequently increasing stiffness. Figure 7(b) displays the loss tangent of the system containing nonsilanized and silanized MMT. The temperature where storage modulus is lowest corresponds to the highest loss tangent. The sample containing silanized MMT shows a lower $\tan \delta$ value, which represents a higher energy dissipation potential of the sample due to the complex intermixing of the glass fiber-silanized MMT and vinylester polymer; that is, the sample does not store the energy provided by the applied stress. On the other hand, the sample without silanized MMT acts as a more elastic material due to the greater storage of provided energy. In addition, $T_{g}$ value of the system shifts to a higher value due to the silanization of MMT.

To study the effect of surface treatment of MMT on mechanical properties of MMT based composites, tensile and bending tests are performed. Both composites show the linear relationship between the tensile strength and strain in Figure 8. Maximum tensile strength and elastic modulus are shown in Figures 9(a) and 9(b), respectively. It is observed that maximum tensile strength and elastic moduli of treated MMT based composites are higher than those of the untreated MMT based composites which is the result of optimal dispersion and enhanced interfacial interaction between surface-treated MMT, glass fiber, and vinylester matrix. The uniformly dispersed MMT layers and glass fibers behave as an obstacle to deformation. When the outside load is applied to the sample, the polymer matrix transfers load to the reinforced nanoclay that aligns into the load direction and reduces the probability of crack generation. Moreover, after silane modification, MMT becomes hydrophobic which improves the compatibility between polymer matrix and MMT [23].

Bending tests are performed to study the flexural strength of untreated and treated MMT composites. Figure 10 shows the stress-strain curve of both samples. Figures 11(a) and 11(b) represent the flexural strength and flexural modulus of both composites, respectively. It is found that the flexural strength and flexural modulus of the surface-modified MMT based composites are slightly higher than those of the untreated MMT based composites. The reason behind this is the fact that after silanization of MMT adhesion between MMT, glass fibers, and matrix increases which inhibits the crack propagation by resisting the fibers to pull out during load application.

SEM images of a fractured surface of untreated and treated MMT GFRP/vinylester composites are shown in Figures 12(a) and 12(b), respectively. As can be seen in Figure 12(a), untreated MMT based composites possess poor adhesion between the matrix and the fillers. Therefore, when a load is applied to the composites, glass fibers pull out because of weak interfacial bonding. The surface of the composites is very rough and contains voids. Since MMT is hydrophilic in nature, there is little interaction between MMT and vinylester, resulting in low interfacial strength, which leads to crack initiation. Moreover, inadequate dispersion of MMT results in agglomeration, which is responsible for the deterioration of mechanical properties. However, Figure 12(b) shows the fractured surface of silanized MMT based composites. As the image reveals, the surface of the composite incorporated with surface-modified MMT is smoother and contains fewer voids. When the surface of MMT is treated with 3-APTES, MMT becomes hydrophobic, altering the chemistry between the host polymer matrix and MMT. This change involves increased interaction between the fillers and matrix which results in strong interfacial bonding and therefore plays a significant role in load transfer [40]. When silane groups are attached to the MMT surface, the interplanar distance between the MMT platelets increases and each platelet acts as a nanoscale entity. Nanodimensional attributes of modified MMT play a crucial role in optimal dispersion in the matrix.

\section{Conclusions}

A systematic investigation of mechanical properties of montmorillonite (1.0 wt.\% as-received and surfacemodified)-based glass fiber-reinforced vinylester composites is described in this report. The results indicate that the tensile and flexural properties of the composites depend upon the interfacial strength between the polymer host and the reinforced materials. Composites having surface-treated MMT reveal better interaction with the reinforced materials and better adhesion, which result in improved tensile and flexural properties of the composites. Because of surface modification, hydrophilic MMT becomes hydrophobic and becomes compatible with the organic polymer matrix. 


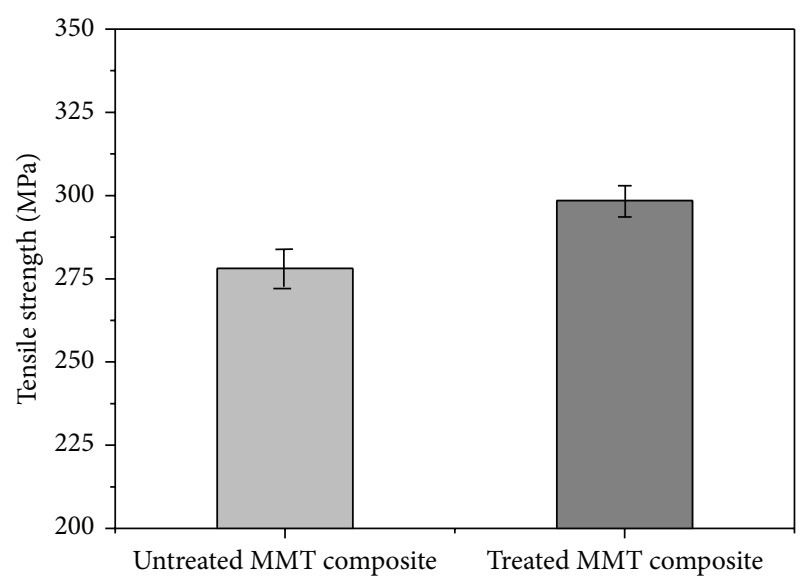

(a)

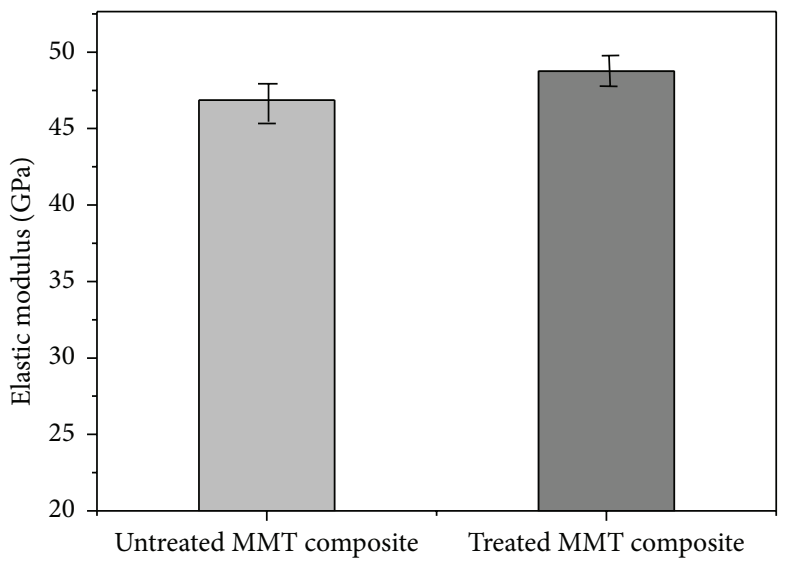

(b)

FIGURE 9: Maximum tensile strength (a) and elastic modulus (b) of tensile specimens of untreated and treated MMT based GFRP/vinylester composites.

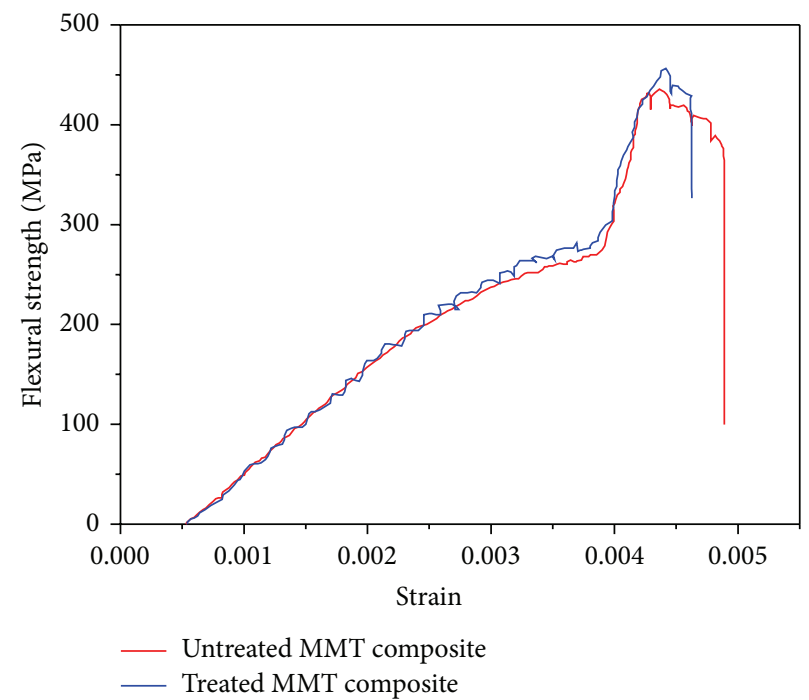

FIGURE 10: Stress-strain curve of bending specimens of untreated and treated MMT based GFRP/vinylester composites.

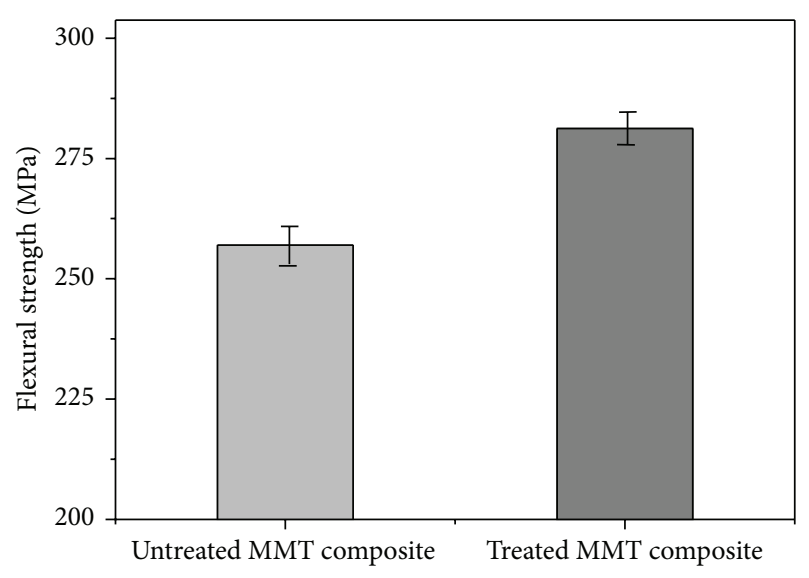

(a)

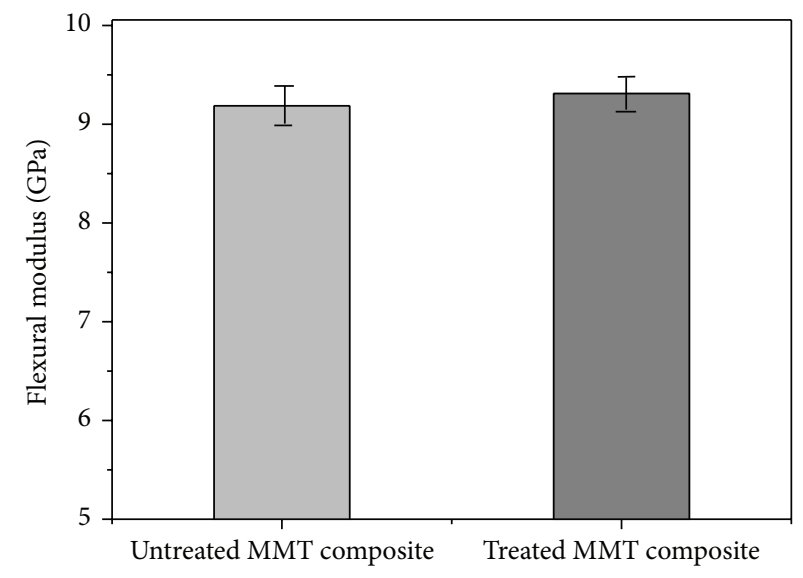

(b)

FIgURE 11: Maximum flexural strength (a) and flexural modulus (b) of bending specimens of untreated and treated MMT based GFRP/vinylester composites. 


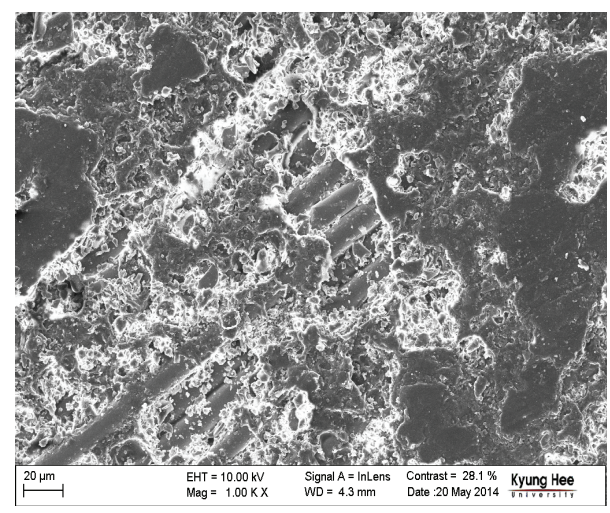

(a)

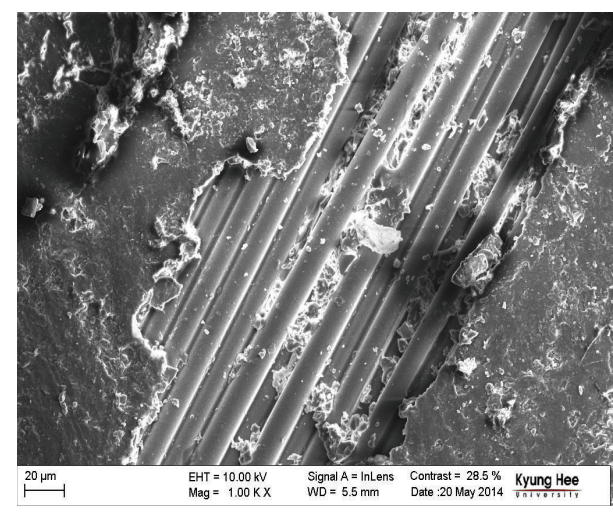

(b)

FIGURE 12: SEM image of fractured surface. (a) Untreated MMT based GFRP/vinylester composites. (b) Treated MMT based GFRP/vinylester composites.

Furthermore, MMT platelets behave as individual entities and disperse as nanoclay into the host matrix. Therefore, these composites may have various mechanical applications.

\section{Conflict of Interests}

The authors declare that there is no conflict of interests regarding the publication of this paper.

\section{Acknowledgment}

This work was financially supported by the National R\&D project of "Development of Energy Utilization technology of Deep Sea Water Resource" supported by the Ministry of Oceans and Fisheries of the Republic of Korea.

\section{References}

[1] M. Yadav, K. Y. Rhee, S. J. Park, and D. Hui, "Mechanical properties of $\mathrm{Fe}_{3} \mathrm{O}_{4} / \mathrm{GO} /$ chitosan composites," Composites Part B: Engineering, vol. 66, pp. 89-96, 2014.

[2] J. Nunes-Pereira, C. M. Costa, and S. Lanceros-Méndez, "Polymer composites and blends for battery separators: state of the art, challenges and future trends," Journal of Power Sources, vol. 281, pp. 378-398, 2015.

[3] M. T. Kim, K. Y. Rhee, I. Jung, S. J. Park, and D. Hui, "Influence of seawater absorption on the vibration damping characteristics and fracture behaviors of basalt/CNT/epoxy multiscale composites," Composites Part B: Engineering, vol. 63, pp. 61-66, 2014.

[4] A. Pourjavadi, S. M. Fakoorpoor, A. Khaloo, and P. Hosseini, "Improving the performance of cement-based composites containing superabsorbent polymers by utilization of nano- $\mathrm{SiO}_{2}$ particles," Materials \& Design, vol. 42, pp. 94-101, 2012.

[5] Y. Kuang and B. Huang, "Effects of covalent functionalization on the thermal transport in carbon nanotube/polymer composites: a multi-scale investigation," Polymer, vol. 56, pp. 563-571, 2015.

[6] J.-H. Lee, K. Y. Rhee, and S. J. Park, "Silane modification of carbon nanotubes and its effects on the material properties of carbon/CNT/epoxy three-phase composites," Composites Part
A: Applied Science and Manufacturing, vol. 42, no. 5, pp. 478483, 2011.

[7] S. Daniel, T. P. Rao, K. S. Rao et al., "A review of DNA functionalized/grafted carbon nanotubes and their characterization," Sensors and Actuators, B: Chemical, vol. 122, no. 2, pp. 672-682, 2007.

[8] P. Michelis and J. Vlachopoulos, "Complete CNT disentanglement-dispersion-functionalisation in a pulsating microstructured reactor," Chemical Engineering Science, vol. 90, pp. 10-16, 2013.

[9] P. Roy and R. R. N. Sailaja, "Chitosan-nanohydroxyapatite composites: mechanical, thermal and bio-compatibility studies," International Journal of Biological Macromolecules, vol. 73, pp. 170-181, 2015.

[10] A. Gharbi, R. B. Hassen, and S. Boufi, "Composite materials from unsaturated polyester resin and olive nuts residue: the effect of silane treatment," Industrial Crops and Products, vol. 62, pp. 491-498, 2014.

[11] F.-P. Du, H. Tang, and D.-Y. Huang, "Thermal conductivity of epoxy resin reinforced with magnesium oxide coated multiwalled carbon nanotubes," International Journal of Polymer Science, vol. 2013, Article ID 541823, 5 pages, 2013.

[12] M.-G. Olivier, M. Fedel, V. Sciamanna et al., "Study of the effect of nanoclay incorporation on the rheological properties and corrosion protection by a silane layer," Progress in Organic Coatings, vol. 72, no. 1-2, pp. 15-20, 2011.

[13] H. Lee, I. Ohsawa, and J. Takahashi, "Effect of plasma surface treatment of recycled carbon fiber on carbon fiber-reinforced plastics (CFRP) interfacial properties," Applied Surface Science, vol. 328, pp. 241-246, 2015.

[14] F. Uddin, "Clays, nanoclays, and montmorillonite minerals," Metallurgical and Materials Transactions A, vol. 39, no. 12, pp. 2804-2814, 2008.

[15] A. I. Alateyah, H. N. Dhakal, and Z. Y. Zhang, "Processing, properties, and applications of polymer nanocomposites based on layer silicates: a review," Advances in Polymer Technology, vol. 32, no. 4, Article ID 21368, 2013.

[16] L. Wang, K. Wang, L. Chen, Y. Zhang, and C. He, "Preparation, morphology and thermal/mechanical properties of epoxy/nanoclay composite," Composites-Part A: Applied Science and Manufacturing, vol. 37, no. 11, pp. 1890-1896, 2006. 
[17] P. C. LeBaron, Z. Wang, and T. J. Pinnavaia, "Polymer-layered silicate nanocomposites: an overview," Applied Clay Science, vol. 15, no. 1-2, pp. 11-29, 1999.

[18] T. P. Mohan and K. Kanny, "Effect of nanoclay in HDPEglass fiber composites on processing, structure, and properties," Advanced Composite Materials, vol. 21, no. 4, pp. 315-331, 2012.

[19] J.-J. Lin, Y.-N. Chan, and Y.-F. Lan, "Hydrophobic modification of layered clays and compatibility for epoxy nanocomposites," Materials, vol. 3, no. 4, pp. 2588-2605, 2010.

[20] A. A. Azeez, K. Y. Rhee, S. J. Park, and D. Hui, "Epoxy clay nanocomposites-processing, properties and applications: a review," Composites Part B: Engineering, vol. 45, no. 1, pp. 308320, 2013.

[21] J. Chandradass, M. R. Kumar, and R. Velmurugan, "Effect of nanoclay addition on vibration properties of glass fibre reinforced vinyl ester composites," Materials Letters, vol. 61, no. 22, pp. 4385-4388, 2007.

[22] A. I. Alateyah, H. N. Dhakal, and Z. Y. Zhang, "Mechanical and thermal properties characterization of vinyl ester matrix nanocomposites based on layered silicate," International Journal of Mechanical, Aerospace, Industrial and Mechatronics Engineering, vol. 7, no. 9, pp. 701-708, 2013.

[23] C.-W. Chiu, T.-K. Huang, Y.-C. Wang, B. G. Alamani, and J.-J. Lin, "Intercalation strategies in clay/polymer hybrids," Progress in Polymer Science, vol. 39, no. 3, pp. 443-485, 2014.

[24] K. Song, Y. Zhang, J. Meng et al., "Structural polymer-based carbon nanotube composite fibers: understanding the processingstructure-performance relationship," Materials, vol. 6, no. 6, pp. 2543-2577, 2013.

[25] B.-W. Jo, S.-K. Park, and D.-K. Kim, "Mechanical properties of nano-MMT reinforced polymer composite and polymer concrete," Construction and Building Materials, vol. 22, no. 1, pp. 14-20, 2008.

[26] P. Uthirakumar, Y. B. Hahn, K. S. Nahm, and Y.-S. Lee, "Exfoliated high-impact polystyrene/MMT nanocomposites prepared using anchored cationic radical initiator-MMT hybrid," European Polymer Journal, vol. 41, no. 7, pp. 1582-1588, 2005.

[27] L. L. Sobrinho, M. Ferreira, and F. L. Bastian, "The effects of water absorption on an ester vinyl resin system," Materials Research, vol. 12, no. 3, pp. 353-361, 2009.

[28] M. J. M. Abadie, K. Mekhissi, and P. J. Burchill, "Effects of processing conditions on the curing of a vinyl ester resin," Journal of Applied Polymer Science, vol. 84, no. 6, pp. 1146-1154, 2002.

[29] W. D. Cook, G. P. Simon, P. J. Burchill, M. Lau, and T. J. Fitch, "Curing kinetics and thermal properties of vinyl ester resins," Journal of Applied Polymer Science, vol. 64, no. 4, pp. 769-781, 1997.

[30] B. Pramanik and P. R. Mantena, "Strain rate dependent ductileto-brittle transition of graphite platelet reinforced vinyl ester nanocomposites," Advances in Materials Science and Engineering, vol. 2014, Article ID 765698, 8 pages, 2014.

[31] B. Pramanik, T. Tadepalli, and P. R. Mantena, "Surface fractal analysis for estimating the fracture energy absorption of nanoparticle reinforced composites," Materials, vol. 5, no. 12, pp. 922-936, 2012.

[32] D. R. Messier and P. J. Patel, "High modulus glass fibers," Journal of Non-Crystalline Solids, vol. 182, no. 3, pp. 271-277, 1995.

[33] R. Park and J. Jang, "A study of the impact properties of composites consisting of surface-modified glass fibers in vinyl ester resin," Composites Science and Technology, vol. 58, no. 6, pp. 979-985, 1998.
[34] K. V. Mahesh, H. N. Murthy, B. E. Kumaraswamy, R. Sridhar, M. Krishna, and B. S. Sherigara, "The influence of montmorillonite on mechanical, thermal and fire retardation properties of vinylester/glass composites," Journal of Composite Materials, vol. 47, no. 17, pp. 2163-2178, 2013.

[35] M. Yigit, T. Seçkin, B. Yigit, and S. Köytepe, "Synthesis and characterization of thermally stable camphor-based polyimideclay nanocomposites," Turkish Journal of Chemistry, vol. 37, no. 2, pp. 182-194, 2013.

[36] S. Subramani, J.-Y. Lee, S.-W. Choi, and J. H. Kim, "Waterborne trifunctionalsilane-terminated polyurethane nanocomposite with silane-modified clay," Journal of Polymer Science Part B: Polymer Physics, vol. 45, no. 19, pp. 2747-2761, 2007.

[37] L. Madaleno, J. Schjødt-Thomsen, and J. C. Pinto, "Morphology, thermal and mechanical properties of PVC/MMT nanocomposites prepared by solution blending and solution blending+melt compounding," Composites Science and Technology, vol. 70, no. 5, pp. 804-814, 2010.

[38] Y. Cai, F. Huang, Q. Wei, E. Wu, and W. Gao, "Surface functionalization, morphology and thermal properties of polyamide6/O-MMT composite nanofibers by $\mathrm{Fe}_{2} \mathrm{O}_{3}$ sputter coating," Applied Surface Science, vol. 254, no. 17, pp. 5501-5505, 2008.

[39] P. R. Rajakumar and R. Nanthini, “Thermal and morphological behaviours of polybutylene terephthalate/ polyethylene terephthalate blend nanocomposites," Rasayan Journal of Chemistry, vol. 4, no. 3, pp. 567-579, 2011.

[40] X. Kornmann, H. Lindberg, and L. A. Berglund, "Synthesis of epoxy-clay nanocomposites: influence of the nature of the clay on structure," Polymer, vol. 42, no. 4, pp. 1303-1310, 2001. 

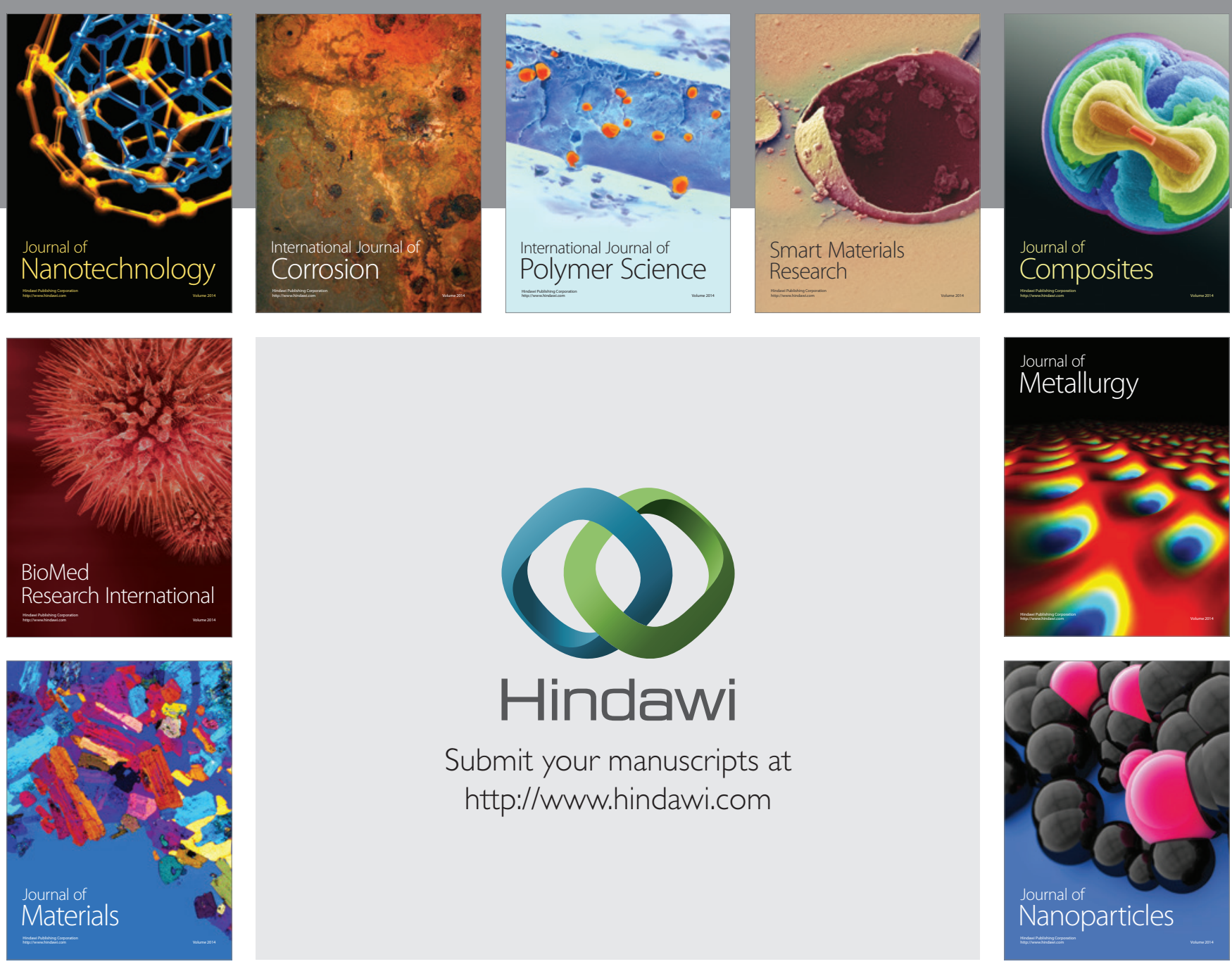

Submit your manuscripts at http://www.hindawi.com
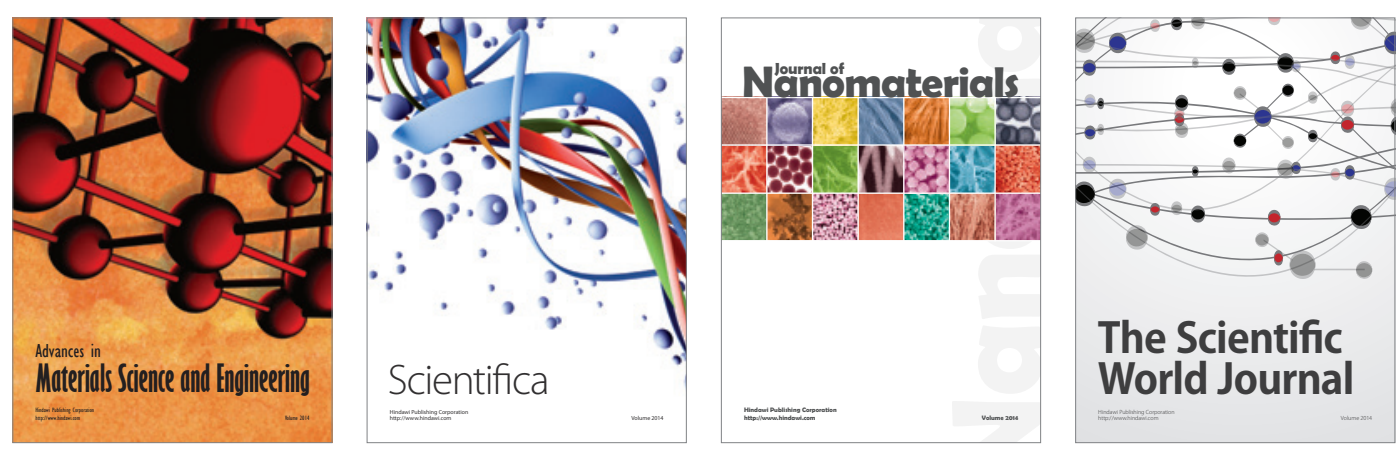

\section{The Scientific World Journal}
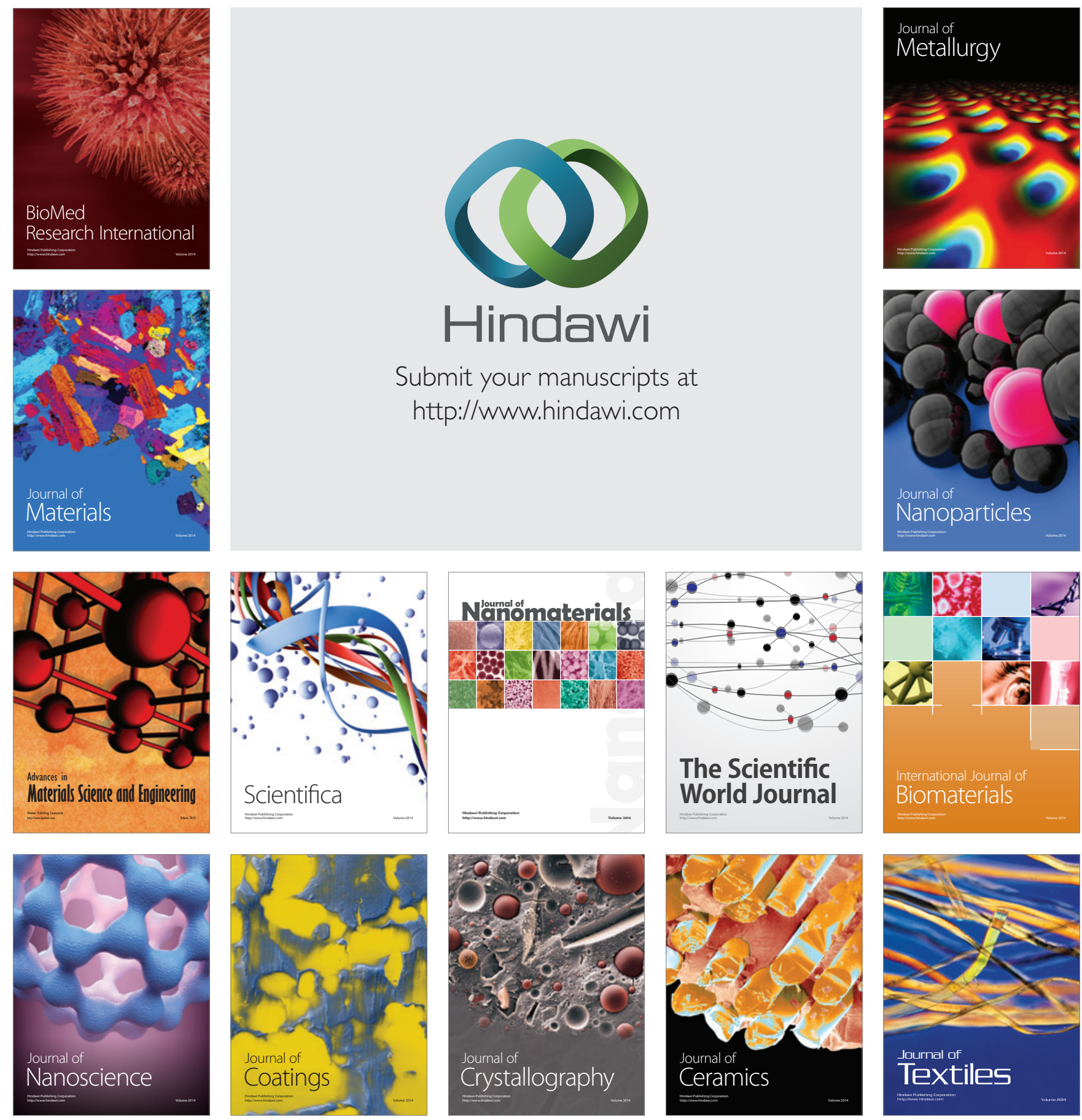